\title{
Staying on track: behavioral engagement of at-risk and non-at-risk students in post-secondary vocational education
}

\author{
Louise Elffers
}

Received: 4 August 2011 /Revised: 29 April 2012 / Accepted: 7 May 2012 /

Published online: 6 June 2012

(C) The Author(s) 2012. This article is published with open access at Springerlink.com

\begin{abstract}
Behavioral disengagement from school is a proximal predictor of dropout. Therefore, the enhancement of behavioral engagement is a useful point of entry for dropout prevention. In this study, we examine the behavioral engagement of at-risk and non-at-risk students in Dutch senior vocational education (SVE), a sector confronted with high dropout rates. Using multilevel regression analyses, we assess the role of students' background characteristics and perceived fit with the school environment in their behavioral engagement. Findings indicate that students in highly urbanized areas are significantly less engaged in school. The perceived proportion of autonomous work is most prominently correlated to students' behavioral engagement. Whereas in general SVE students are more engaged if their program requires little autonomous work from students, engineering students appear to favor autonomous work forms.
\end{abstract}

Keywords Vocational education · Behavioral engagement · At-risk students

\section{Introduction}

The prevalence of school dropout is a major problem in many Western societies. Dropping out of school increases the chance of unemployment and poverty in later life, and can incite frustration and disappointment (Bridgeland et al. 2006; Research Centre for Education and the Labour Market 2009). Various student characteristics, such as a low socioeconomic status or an ethnic minority background, have been found to signify an increased risk for dropout (Ekstrom et al. 1986; Rumberger 1987; Wehlage et al. 1989). However, such risk indicators fail to elucidate the proximal mechanisms that push or pull students out of school, and do not allow for interventions to enhance the school careers of at-risk students

Current themes of research: post-secondary vocational education; dropout; student engagement; school transitions.

L. Elffers $(\bowtie)$

Research Institute Child Development and Education, University of Amsterdam, P.O. Box 94208, 1090

GE Amsterdam, The Netherlands

e-mail: 1.elffers@uva.nl

URL: www.uva.nl 
(Alexander et al. 2001; Finn 1993; Rumberger 1987). Therefore, researchers try to uncover the factors associated with an increased risk for dropout that are more manipulable (Finn and Voelkl 1993). A proximal predictor of dropout that has been identified across diverse educational settings is behavioral disengagement in school (Finn and Rock 1997; Fredricks et al. 2004; Janosz et al. 2000; Rumberger 1987). Behavioral engagement refers to the active involvement of students in school, such as regular attendance of classes, arriving in class on time, paying attention to the teacher, and completing assigned work (Finn 1993). Behavioral engagement is a prerequisite for performance and persistence in school (Ekstrom et al. 1986; Finn 1989; Finn and Rock 1997), and high levels of behavioral engagement may explain why some at-risk students succeed in school whereas others do not (Finn 1993; Finn and Voelk1 1993). Therefore, behavioral engagement has been labeled "the most proximal point of entry" (Connell et al. 1994, p. 504) and "the most promising approach" (Appleton et al. 2006, p. 427) for dropout prevention.

To design school-based interventions that enhance the school careers of all students, we need to determine how behavioral engagement is related to school and classroom contexts. For instance, it is important to find out whether it is more important to alter teacher-student relationships, the curriculum, or both, to increase students' engagement in school (Finn 1993; Fredricks et al. 2004). However, individuals may differ substantially in their perceptions of the institutional context (Roeser et al. 2009), and it is students' personal interpretation of the context, or their perceived fit with that context, that most directly determines their behavior (Eccles 1983; Jang et al. 2010; Roeser et al. 2009; Tinto 1993; Wessel et al. 2008). Some aspects of the institutional context may be particularly important for the engagement of at-risk students. For instance, as students from disadvantaged backgrounds often have less access to supportive resources in their home environment (Roderick 1993; Roderick and Camburn 1999), their engagement in school may be more dependent on support from teachers and school staff (Fredricks et al. 2004; Furrer and Skinner 2003; Scientific Council for Government Policy 2008). Therefore, it is important to study the correlates of school engagement among students from various backgrounds. However, most research on student engagement has been conducted with data from predominantly White middle-class samples (Fredricks et al. 2004; Furrer and Skinner 2003; Wang et al. 2010; Zimmer-Gembeck et al. 2006). Moreover, most engagement research has been carried out in Anglo-Saxon school settings (Fredricks et al. 2004).

\section{This study}

In this study, we expand the focus in behavioral engagement research to other populations and educational settings. We examine the role of various student background characteristics and students' perceived fit with the school environment in their behavioral engagement in senior vocational education (SVE) in the Netherlands. SVE is the senior continuation of the vocational track in Dutch secondary education, offering specialized job-oriented vocational programs for students aged 16 years and older. Similar to several neighboring European countries, the vocational track educates a substantial proportion of the secondary and post-secondary student population in the Netherlands. Job-oriented programs, like those in SVE, have been suggested to increase the school engagement and performance for a larger group of students than general academic programs, like the regular high school track in the USA, do (Newmann 1992; Scientific Council for Government Policy 2008; Symonds et al. 2011). Yet, dropout rates in the Netherlands peak in SVE (Dutch Ministry of Education Culture and Science 2011b), suggesting that many students in SVE are in a process of disengagement from school that may culminate in dropout. A substantial proportion of SVE students can be labeled at-risk for 
dropout on the basis of sociodemographic characteristics, such as coming from a lower socioeconomic or ethnic minority background, or, to a lesser extent, on the basis of conditions outside school, such as teenage pregnancy or delinquency (Dutch Ministry of Education Culture and Science 2009; Kuhry 1998; Scientific Council for Government Policy 2008). Hence, SVE provides a very relevant, but thus far understudied, context to study the correlates of behavioral engagement in school among at-risk and non-at-risk students. Below, we will set out the theoretical framework that guided the selection of variables in our study.

\section{Theoretical framework}

\section{Behavioral engagement}

The concept of behavioral engagement refers to the behavioral dimension of the multidimensional construct of school engagement, which comprises students' behavioral and emotional dispositions to school (Fredricks et al. 2004). The emotional dimension of school engagement refers to students' school-related attitudes, interests, and values, whereas behavioral engagement pertains to their active participation in the school setting. According to Finn's participationidentification model, behavioral engagement forms the starting point of a self-reinforcing cycle of engagement and performance in school: participation promotes school performance, which in turn promotes positive identification with school (Finn 1989). Finn distinguished four consecutive levels of behavioral engagement, ranging from elementary involvement in class activities to participation in extracurricular activities and school governance (Finn 1989). As participation in extracurricular activities or student councils is rare in SVE schools, we will focus on participation in class-related activities only in this study.

\section{Student background characteristics associated with dropout}

As behavioral disengagement is a precursor of dropout, it is important to examine whether differences in behavioral engagement between certain groups of students mirror differences in their propensity to drop out. Sociodemographic background characteristics are the most commonly used indicators of the risk for dropout. Students from lower socioeconomic backgrounds, indicated by lower levels of parental education and employment and restricted financial resources in the family, are overrepresented in dropout statistics (Alexander et al. 2001; Battin-Pearson et al. 2000; Ekstrom et al. 1986; Rumberger 1987; Rumberger and Lim 2008; Wehlage et al. 1989). Ethnic minority students drop out at higher rates than native students (Dutch Ministry of Education Culture and Science 2011a; Ekstrom et al. 1986). Other sociodemographic risk indicators are growing up in a single parent home or living alone (Barrington and Hendricks 1989; Dutch Ministry of Education Culture and Science 2011a), being male, and being of older age (Battin-Pearson et al. 2000; Dutch Ministry of Education Culture and Science 2011a; Ekstrom et al. 1986; Rumberger 1987; Rumberger and Lim 2008). Various studies point towards the limited access to supportive resources to assist students in their school careers, such as encouragement and support from family and friends, as an explanation for the differences in dropout rates between sociodemographic groups (Alexander et al. 1994; Audas and Willms 2001; Kao and Tienda 1998; Roderick 1993). Not only sociodemographic student characteristics but also students' personal circumstances and behaviors outside school affect their probability to drop out (Finn 1993). Pregnancy and parenthood, the use of drugs, delinquent behavior, personal debts, and intensive jobs next to school have all been found to increase the risk for dropout (Dutch 
Ministry of Education Culture and Science 2011a; Ekstrom et al. 1986; Lee and Staff 2007; Roebuck et al. 2004; ter Bogt et al. 2009; Verhagen et al. 2010). Last, the risk for dropout differs according to educational track and school district. Students in lower level programs in SVE drop out more often, as do students in economics and engineering programs (Dutch Ministry of Education Culture and Science 2011a). Also, if students have dropped out of a program before, have repeated a grade, or changed schools, they are more likely to drop out (Astone and McLanahan 1991; Jimerson et al. 2002). Students in highly urbanized school districts drop out more often than students in less urbanized or rural school districts (Dutch Ministry of Education Culture and Science 2011a).

\section{The role of school experiences}

School engagement is not generated by students alone (Wehlage et al. 1989). Instead, it evolves from the interaction between the individual student and the school context (Fredricks et al. 2004). It is important to find out which aspects of the school context help or hamper students' behavioral engagement in school. However, effects of institutional characteristics on educational outcomes are generally small and appear to be mediated by the experiences that students have in the school environment (Pascarella and Terenzini 2005; Roeser et al. 2009). Various studies attest to the centrality of students' individual experiences as critical determinants of a range of educational outcomes, over and above objective characteristics of the institutional context (Eccles 1983; Furrer and Skinner 2003; Jang et al. 2010; Wessel et al. 2008). For instance, Tinto's renowned model of institutional departure revolves around students' perceptions of the degree to which their experiences in the school environment match their needs and interests (Tinto 1993). If students perceive a mismatch between the institutional environment and their personal needs and interests, withdrawal is likely (Eccles and Midgley 1989; Finn 1993; Miller et al. 1988; Tinto 1993). In this study, we adopt a similar perspective, by taking students' perceived fit with their school environment as our point of departure.

Students engage in social and academic interactions with various actors in the school environment. Their behavioral engagement can be promoted or discouraged by their perceived fit with fellow students, school staff, the curriculum, and the school climate (Freeman et al. 2007; Tinto 1993; Wang et al. 2010; Wehlage et al. 1989). Previous research suggests that student engagement is particularly promoted if the school environment meets the "basic needs" for autonomy, relatedness, and competence (Connell and Wellborn 1991; Reeve et al. 2004; ZimmerGembeck et al. 2006). A school environment that enables students to feel competent, autonomous and related (Connell and Wellborn 1991), or, in other words, to develop a sense of selfdetermination (Reeve et al. 2004), encourages them to actively engage in school. For instance, an autonomy supportive school environment that encourages students to self-direct their learning processes is more likely to incite active class participation and task completion (Jang et al. 2010; Marks 2000; National Research Council, and Institute of Medicine 2004; Zimmer-Gembeck et al. 2006). However, self-directed learning processes cannot be successful without structured guidance (Jang et al. 2010; National Research Council, and Institute of Medicine 2004; Scientific Council for Government Policy 2008). A structured environment, with clear rules and expectations, enhances student engagement (Finn 1993; Newmann 1992; Wang et al. 2010) and may be particularly essential for students who come from a less structured home environment (Scientific Council for Government Policy 2008). The optimal mix of autonomy support and structure has yet to be determined (Fredricks et al. 2004), and is topic of public debate in the Netherlands. The recent transformation of SVE programs into competency-based curricula that require more student autonomy has led to complaints from students, teachers, and parents about a lack of guidance and structure (Commissie Dijsselbloem 2008). 
The need for relatedness refers to the human need to feel part of a group (Baumeister and Leary 1995; Wehlage et al. 1989). Positive perceptions of the dominant culture of the institution and positive interactions with key actors in the institutional environment have been found to promote students' behavioral engagement (Furrer and Skinner 2003; Newmann 1992; Roeser et al. 2009; Steinberg et al. 1992; Tinto 1993). A sense of relatedness, especially to teachers, can serve as an important resource for students who face difficulties in their school careers (Furrer and Skinner 2003; Roeser et al. 2009; Scientific Council for Government Policy 2008). A recent national policy report about dropout prevention highlights the importance of a sense of relatedness for the school success of atrisk students, as well as the crucial role of teacher support to establish such relatedness (Scientific Council for Government Policy 2008).

The need for competence refers to the experience of academic fit. If students perceive the academic curriculum as relevant and helpful in terms of their educational and career goals, and if they perceive that they have what it takes to succeed, they are more likely to actively engage in class work (Crumpton and Gregory 2011; Tinto 1993). A practice-oriented focus in education, with authentic tasks that are clearly related to the workplace and the "real world" outside school, has been advocated to increase the school engagement of less school-oriented youth in particular (Newmann 1992; Scientific Council for Government Policy 2008).

\section{Research questions}

In this study, we examine the behavioral engagement of a diverse sample of students in SVE, including a substantial proportion of students with background characteristics that are associated with an increased risk for dropout. Research question 1, Do student background characteristics associated with an increased risk for dropout relate to lower levels of behavioral engagement in SVE?, assesses differences in behavioral engagement between at-risk and non-at-risk students in SVE. To distinguish between at-risk and non-at-risk students, we include sociodemographic indicators, personal conditions and behaviors outside school, educational status characteristics, and a measure on students' perceived access to supportive resources outside school. Research question 2, To what extent is behavioral engagement in SVE related to students' perceived fit with the school environment?, examines the relationship between students' perceptions of the school environment and their behavioral engagement. We look at students' perceived fit with the academic program, teachers, classmates, and the school climate. Moreover, we take into account three separate variables to specifically measure the perceived proportion of autonomous work in the program, the perceived strictness of school rules, and the perceived difficulty of the program. Last, we estimate interaction effects of student background characteristics and perceived fit with the school environment on students' behavioral engagement, to answer research question 3: Does the relationship between the perceived fit with the school environment and behavioral engagement differ between at-risk and non-at-risk students?

\section{Methods}

Sample and data collection

The data in this study come from a longitudinal study on student persistence in the first year in SVE. From this study, we selected all 909 students of whom data were available regarding 
their behavioral engagement, school experiences, and individual background characteristics. To obtain a diverse sample of at-risk and non-at-risk students, out of the total of 40 regional SVE school boards in the Netherlands, 10 school boards that are located in highly and intermediate urban areas were invited for participation in the study, of which five agreed to participate. Within each school board, first year groups were selected from engineering, economics, and health and social care programs at all four SVE degree levels (1-assistant level, 2-basic vocational level, 3-full professional level, 4-specialist level). The groups were selected during the summer break before individual students were assigned to the groups. The data for this study are from the second data collection wave in which 60 groups participated with an average group size of 15 students. Data were collected at the start of the spring semester in 2009. The questionnaires were completed in a classroom setting under supervision of a teacher. All teachers were informed about the purpose of the study and received an instructional handout. A short introductory statement about the purpose of the study was printed on the questionnaire, as well as a short privacy statement to assure students that no identifiable personal data would be disclosed. Students handed in their questionnaire in a blank envelope. Although participation in the study was voluntary for all students, we received no reports of students not willing to participate. The descriptives of the sample in Table 1 indicate that our sample corresponds satisfactorily to available statistics of vocational education and urban schools in the Netherlands (Dutch Ministry of Education Culture and Science 2011b; Dutch Ministry of Health Welfare and Sport 2010; Knowledge Centre for Vocational Training and Labour Market 2010; Kuhry 1998; Scientific Council for Government Policy 2008).

\section{Variables and measures}

Data were collected using a self-report questionnaire that was developed to suit the specific context of SVE and its students. Items were partly based on previous questionnaires on school experiences and engagement in American and Dutch educational settings (Beekhoven 2002; Goodenow and Grady 1993; Pascarella and Chapman 1983; Voelk1 1995; Willms 2003). All items were measured with statements, to which students responded on a five-point Likert-type scale (strongly disagree, disagree, neutral, agree, strongly agree), except for the items on students' background characteristics. Three items, on students' perceptions of the difficulty of the degree program, the proportion of autonomous work in the program, and the strictness of school rules and regulations, had an alternative scale, to enable respondents to report less optimal experiences on both the "too much" and the "too little" side of the spectrum. The questionnaire was subjected to a pilot study before being finalized. Exploratory factor analysis (principal component analysis with oblimin rotation) on all predictor items with a five-point scale indicated five components with a cumulative percentage of explained variance of $47 \%$. These components allowed for a clear interpretation and were labeled perceived fit academic program, perceived academic support, perceived social support, perceived fit classmates, and perceived fit school climate. Students' school board, vocational sector, and program level were pre-printed on the questionnaires.

The outcome variable, behavioral engagement, was measured using a scale consisting of eight items $[\alpha=0.76$, e.g., I attend most classes; and During class, I often engage in other activities than class work, such as chatting, msn, texting, internet (reversed)].

The explanatory variables comprised measures of students' social and academic school experiences and background. Academic school experience measures included students' perceived fit with the academic program (perceived fit academic program-10 items, $\alpha=0.82$, e.g., 
Table 1 Descriptives of sample of 909 students in senior vocational education $\begin{array}{ll}\text { Characteristics } & \%\end{array}$

Regional school board

School board 1 (highly urbanized area) 20

School board 2 (highly urbanized area) 20

School board 3 (highly urbanized area) 20

School board 4 (intermediate urbanized area) 8

School board 5 (intermediate urbanized area) 33

SVE sector

Economics $\quad 30$

Engineering 33

$\begin{array}{ll}\text { Health and social care } & 37\end{array}$

SVE degree program level

Level 1

Level 2

Level 3

Level $4 \quad 32$

Prior education

PVE with diploma $\quad 66$

PVE without diploma 4

SVE with diploma $\quad 8$

SVE without diploma 9

Other 13

Gender

Female $\quad 54$

Male 46

Ethnic identity

Native Dutch background 53

Moroccan background $\quad 15$

$\begin{array}{ll}\text { Turkish background } & 12\end{array}$

Surinamese background 9

Antillean background $\quad 2$

Other ethnic background $\quad 9$

Age

16-17 years $\quad 62$

18-19 years 30

Older than 19 years $\quad 8$

Household

Living with both parents $\quad 65$

Living with one parent $\quad 24$

Living alone $\quad 3$

Living with other relatives/friends $\quad 8$

Job status parents

Both parents have a job 49

One parent has a job $\quad 23$

Both parents are unemployed 14

Student does not know $\quad 14$ 
Table 1 (continued)

\begin{tabular}{ll}
\hline Characteristics & $\%$ \\
\hline Highest education parents & 21 \\
Secondary education or less & 20 \\
SVE or similar & 18 \\
Higher education or similar & 41 \\
Student does not know & 20 \\
Financial problems in family & 10 \\
Personal debts student & 4 \\
Student (or partner) is pregnant/has child(ren) & 17 \\
Student has been arrested by the police & 11 \\
Student uses (soft) drugs & \\
Extra job student & 39 \\
No extra job & 19 \\
$<8$ h a week & 34 \\
$8-15$ h a week & 8 \\
$>15$ h a week &
\end{tabular}

I find the content of the program interesting) and their perceptions of the academic support provided by school staff (perceived academic support - nine items, $\alpha=0.85$, e.g., Teachers support me well if I have questions about a task). Moreover, two single-item measures were used to specifically tap students' perceptions of the difficulty of the degree program (perceived difficulty degree program) and of the proportion of autonomous work in the program (perceived proportion of autonomous work). Social school experience variables included students' perceived fit with classmates (perceived fit classmates - six items, $\alpha=0.77$, e.g., I get along well with most of my classmates), with the school climate (perceived fit school climate - nine items, $\alpha=0.82$, e.g., I feel safe at this school), their perceptions of the social support provided by school staff (perceived social support-10 items, $\alpha=0.90$, e.g., School staff support me when I don't feel well), and a single-item measure on the perceived strictness of school rules and regulations (perceived strictness school rules).

Variables concerning students' background included students' self-reported sociodemographic background characteristics (age, gender, ethnic identity, household composition, job status parents, highest educational level parents, financial status of the family), a measure of perceived supportive resources in students' home environment (school support in communityfive items, $\alpha=0.70$, e.g., I can discuss school issues with my parents), and measures concerning personal circumstances and behaviors outside school that are associated with an increased risk for dropout: having a child/(partner) being pregnant, personal debts, drug abuse, having been arrested by the police, and having an extra job. Last, we included school-related background characteristics of all students (prior education, regional school board, vocational sector, and level of current degree program).

\section{Statistical analysis}

We screened the data for meeting the assumptions of regression analysis. The outcome variable was normally distributed, with skewness and kurtosis values between -1 and 1 . A strong correlation $(r=0.7)$ was found between two predictors: perceived academic support and perceived social support. To prevent multicollinearity problems in our regression 
analyses, we merged these two scales into one variable perceived support school staff $(\alpha=0.92)$. All categorical variables were dummy-coded for the analyses. Missing values were limited $(<2 \%$ across all items). As we detected no obvious patterns in missing values, we applied the expectation maximization algorithm (SPSS Inc 2010). The intra-class correlation coefficient of 0.04 indicated that part of the variance could be attributed to between-class differences (Snijders and Bosker 1999), and empty model fit improved significantly $(p<0.01)$ by including class level as a second level. To correct within-class variance estimations for between-class differences, we conducted multilevel regression analyses with class and student as two separate levels. To facilitate interpretation of the scores, variables were standardized to zero mean (grand mean) and unity variance. In model 1 , we only included student background characteristics; in model 2, we added the school experience variables. Last, we examined first-order interaction effects between background characteristics and school experiences on students' behavioral engagement in school.

\section{Results}

Main effects

Table 2 presents the results for the two models. Model 1 shows the standardized regression coefficients for a model that includes students' background characteristics only. Model 2 shows the coefficients for a model with school experience variables added. We find a few differences in behavioral engagement that relate to students' sociodemographic background characteristics. Younger students report slightly less behavioral engagement, but this difference disappears as soon as their school experiences are taken into account. If both parents are unemployed, students score higher on behavioral engagement. Perceived encouragement and support from parents and peers has a significant positive association with behavioral engagement. Students who have debts and students who use drugs are significantly less engaged in school. When controlling for school experiences in model 2, we find a negative relationship between prior dropout from an SVE program and behavioral engagement in the current program. Last, we find that students in school boards in highly urbanized areas are less engaged than students from school boards in intermediate urbanized areas.

School experiences play a prominent role in engagement. Students' behavioral engagement is positively related to their perceptions of the support from school staff, the perceived fit with classmates, and in particular to the perceived fit with the academic program. Perceived fit with the school climate appears to be negatively related to behavioral engagement. However, the fit with school climate shows a small positive correlation with behavioral engagement in a zero-order correlation model. Apparently, its positive influence is suppressed when the other school experience variables are added to the model. The perceived proportion of autonomous work in the program plays a significant role in behavioral engagement: students are more engaged if they perceive that there is limited opportunity for autonomous working in the program. Behavioral engagement is not significantly related to students' perceptions of the difficulty of the program or the strictness of school rules.

\section{Interaction effects}

We examined interaction effects between all student background characteristics and school experience measures. Below, we highlight two interesting patterns of interaction effects that 
Table 2 Regression coefficients of two models predicting students' behavioral engagement in senior vocational education

Behavioral engagement

\begin{tabular}{|c|c|c|}
\hline \multicolumn{2}{|l|}{$\mathrm{ICC}=0.04$} & \\
\hline \multicolumn{2}{|c|}{$\operatorname{Mean}^{\mathrm{a}}=3.82$} & \\
\hline \multicolumn{2}{|l|}{$\mathrm{SD}=0.53$} & \\
\hline Model 1 & Model 2 & \\
\hline$\beta(\mathrm{SE})$ & $\beta(\mathrm{SE})$ & $p$ \\
\hline
\end{tabular}

Background student

Sociodemographic background

Year of birth

Male (vs. female)

Ethnic identity (vs. native Dutch)

Moroccan background

Turkish background

Surinamese background

Antillean background ${ }^{\mathrm{C}}$

Other ethnic background

Household (vs. living with two parents)

$-0.08(0.04)$
$0.17(0.09)$
$-0.02(0.11)$
$0.07(0.11)$
$0.06(0.13)$
$-0.38(0.25)$
$-0.01(0.12)$
$-0.12(0.20)$
$-0.08(0.08)$
$-0.13(0.13)$
$0.35(0.11)^{* *}$
$0.10(0.08)$
$0.12(0.11)$

$0.036^{*}$
0.079
0.646

0.142

$0.15(0.09)$

0.094

0.774

0.624

$-0.09(0.10)$

$0.07(0.10)$

$0.02(0.12)$

$-0.16(0.24)$

$0.02(0.11)$

Living alone

$-0.06(0.19)$

$-0.03(0.08)$

Living with one parent

$-0.02(0.12)$

Job status parents (vs. both parents have a job)

$0.018 *$

0.979

Both parents are unemployed

One parent has a job

Student does not know

Highest education parents (vs. SVE or similar)

Secondary education or less

$0.02(0.10)$

Higher education

$0.01(0.10)$

Student does not know

$0.03(0.09)$

Financial difficulties family (vs. no difficulties)

$-0.03(0.08)$

$0.28(0.10)^{* *}$

0.062

$0.10(0.08)$

$0.10(0.11)$

0.993

Supportive resources in home community

Encouragement and support parents and peers

Circumstances and behavior outside school

Student (or partner) expects/has child(ren) (vs. not)

$0.29(0.03)$

$0.000 * * *$

$0.20(0.03)$

$0.000 * * *$

Personal debts student (vs. no debts)

$0.10(0.17)$

0.553

$0.26(0.16)$

0.105

$-0.28(0.12)$

$0.022 *$

$-0.24(0.11)$

$0.035 *$

$-0.38(.11)$

$0.000 * * *$

$-0.34(0.10)$

$0.001 * * *$

Student has been arrested by the police (vs. not)

$-0.18(0.09)$

0.057

$-0.16(0.08)$

0.058

0.509

0.553

Extra job student (vs. no extra job)

$-0.04(0.09)$

$-0.03(0.08)$

$-0.00(0.07)$

$0.03(0.07)$

$8-15$ h a week

$-0.17(0.12)$

$-0.13(0.11)$

School-related background

Prior education (vs. PVE with diploma) ${ }^{\mathrm{d}}$

0.680

PVE without diploma 
Table 2 (continued)

\begin{tabular}{|c|c|c|c|c|}
\hline & \multicolumn{4}{|c|}{ Behavioral engagement } \\
\hline & \multicolumn{4}{|l|}{$\mathrm{ICC}=0.04$} \\
\hline & \multicolumn{4}{|l|}{ Mean $^{\mathrm{a}}=3.82$} \\
\hline & \multicolumn{4}{|l|}{$\mathrm{SD}=0.53$} \\
\hline & \multicolumn{2}{|l|}{ Model 1} & \multicolumn{2}{|l|}{ Model 2} \\
\hline & $\beta$ (SE) & $p$ & $\beta(\mathrm{SE})$ & $p$ \\
\hline SVE without diploma & $-0.16(0.12)$ & & $-0.25(0.12)^{*}$ & \\
\hline Other prior education & $0.03(0.10)$ & & $-0.01(0.10)$ & \\
\hline Regional school board (vs. school board 5) & & $0.009 * *$ & & $0.004 * *$ \\
\hline School board 4 (intermediate urbanized area) & $0.03(0.13)$ & & $-0.07(0.12)$ & \\
\hline School board 3 (highly urbanized area) & $-0.28(0.11)^{*}$ & & $-0.27(0.09)^{* *}$ & \\
\hline School board 2 (highly urbanized area) & $-0.22(0.10)^{*}$ & & $-0.27(0.09)^{* *}$ & \\
\hline School board 1 (highly urbanized area) & $-0.35(0.11)^{* * *}$ & & $-0.36(0.09)^{* * *}$ & \\
\hline SVE sector (vs. health and social care) & & 0.951 & & 0.731 \\
\hline Economics & $-0.03(0.09)$ & & $0.01(0.08)$ & \\
\hline Engineering & $-0.02(0.12)$ & & $-0.06(0.11)$ & \\
\hline SVE degree program level (vs. level 4) & & 0.992 & & 0.866 \\
\hline Level 1 & $0.04(0.13)$ & & $0.04(0.12)$ & \\
\hline Level 2 & $0.02(0.09)$ & & $-0.04(0.08)$ & \\
\hline Level 3 & $0.02(0.10)$ & & $-0.04(0.09)$ & \\
\hline \multicolumn{5}{|l|}{ School experiences } \\
\hline Perceived fit academic program & & & $0.22(0.04)$ & $0.000 * * *$ \\
\hline Perceived support school staff & & & $0.15(0.05)$ & $0.002 * *$ \\
\hline Perceived fit classmates & & & $0.15(0.03)$ & $0.000 * * *$ \\
\hline Perceived fit school climate & & & $-0.12(0.04)$ & $0.003^{* *}$ \\
\hline Perceived strictness school rules (vs. just right) & & & & 0.498 \\
\hline Very lenient & & & $0.06(0.09)$ & \\
\hline Very strict & & & $-0.06(0.08)$ & \\
\hline Perceived difficulty degree program (vs. just right) & & & & 0.279 \\
\hline Very easy & & & $0.10(0.07)$ & \\
\hline Very difficult & & & $-0.04(0.09)$ & \\
\hline Perceived proportion autonomous work (vs. just r.) & & & & $0.005^{* *}$ \\
\hline Very little & & & $0.28(0.11)^{* *}$ & \\
\hline Very much & & & $-0.09(0.07)$ & \\
\hline Explained variance $^{\mathrm{b}}$ & $R^{2}=0.19$ & & $R^{2}=0.29$ & \\
\hline
\end{tabular}

$n=909, N=60, * p<0.05, * * p<0.01,{ }^{* * *} p<0.001$. Two-tailed test. Not shown: intercept

${ }^{\text {a }}$ Mean on a scale from 1 (very negative) to 5 (very positive)

${ }^{\mathrm{b}}$ Shown: student level variance

${ }^{\mathrm{c}} n=15$

${ }^{\mathrm{d}} P V E$ pre-vocational education, $S V E$ senior vocational education

were identified. In general, the interaction effects indicate that the role of school experiences in students' behavioral engagement varies substantially between students from different 
backgrounds. For instance, while some students are less engaged in the case of a difficult program (Turkish students $-\beta=-0.81, p<0.05$; level 1 students $-\beta=-0.83, p<0.05$ ), others appear to be more engaged if they think that their program is difficult (other ethnic backgrounds $-\beta=0.75, p<0.05$; living with other relative or friends $-\beta=0.73, p<0.05$ ). Similarly, some students participate more if they perceive the program as easy (family with financial difficulties $-\beta=0.39, p<0.05$; single parent families $-\beta=0.36, p<0.05$ ), whereas others participate less when they think that the program is easy (prior education PVE without diploma- $\beta=-0.86, p<0.01$ ). An equally divergent picture is found with regard to the perceived amount of autonomous work that is required in SVE programs. Students in engineering programs are more engaged if they perceive that they are required to work autonomously a lot $(\beta=0.46, p<0.01)$, whereas students in health and social care are less engaged in the case of much perceived autonomy $(\beta=-0.33, p<0.01)$, and more engaged if they experience little autonomy $(\beta=0.45, p<0.01)$.

Another pattern of interaction effects indicates that the behavioral engagement of some groups of at-risk students is less affected by positive school experiences. Examples of this pattern are negative interaction effects with respect to perceived fit with the academic program (other ethnic background $-\beta=-0.43, p<0.001$; living with other relatives or friends $-\beta=$ $-0.26, p<0.05$; living with a single parent $-\beta=-0.14, p<0.05$ ), and with respect to perceived support school staff (Surinamese students $-\beta=-0.36, p<0.001$; other ethnic backgrounds $-\beta=-0.25, p<0.05$; financial difficulties $-\beta=-0.17, p<0.05$; living with other relatives and friends $-\beta=-0.36, p<0.01$; parental education unknown $-\beta=-0.17, p<0.05$ ).

\section{Discussion}

Behavioral engagement of at-risk and non-at-risk students

With a few notable exceptions, individual background characteristics that are associated with an increased risk for dropout are not associated with lower levels of behavioral engagement in school. Although behavioral disengagement is considered a proximal predictor of dropout in educational research (Finn and Rock 1997; Fredricks et al. 2004; Janosz et al. 2000; Rumberger 1987), this study shows that the dropout risk that seems to be embedded in the backgrounds of certain students is not mirrored in differences in behavioral engagement in SVE. Exceptions are the significantly lower engagement of students who use (soft) drugs and students with debts. The devastating impact of drugs on school careers has been reported in various studies (Roebuck et al. 2004; ter Bogt et al. 2009). The negative influence of debts has mostly been described from the perspective of intensive jobs that distract students with financial problems from school (Lee and Staff 2007; Verhagen et al. 2010). However, our results reveal a negative relationship between debts and school engagement after controlling for working hours next to school. This finding suggests that debts may not only form a practical but also an emotional burden for students, which may negatively affect their school career. The significant correlation between school support in the community and behavioral engagement confirms the importance of supportive resources outside school for students' engagement inside school (Roderick 1993; Roderick and Camburn 1999). The inclusion of a measure of supportive resources may explain why individual sociodemographic characteristics play a limited role in our models. Students with two unemployed parents are significantly more engaged in school. It could be that parents who do not work full time have better opportunities to actively monitor their children's participation in school, such as getting up in the morning, leaving for school in time, and making homework. Another 
possible explanation is that students from unemployed parents work extra hard in school to avoid future unemployment for themselves. Last, we find a worrisome result with respect to students who have been previously enrolled in an SVE program without successfully finishing this program: their significantly lower behavioral engagement suggests that they are losing track once again. This finding underlines the continuity of engagement processes in school, as presented in Finn's participation-identification model (Finn 1989).

The lower engagement of students in large cities

We find a remarkable difference in the behavioral engagement between students from school boards in highly urbanized and intermediate urbanized areas. Students in highly urbanized areas report significantly less engagement in school. This difference aligns with regional differences in dropout rates in the Netherlands (Dutch Ministry of Education Culture and Science 2011a). These differences hold after controlling for students' background characteristics and school experiences. SVE school boards comprise a number of different school locations that are managed by one central board of directors. It is possible that organizational features of school boards can explain the differences between the five school boards in our study. However, as the three school boards in highly urbanized areas cluster in their lower scores on behavioral engagement, it may be more plausible to interpret the school board variable in our study as an indicator of the neighborhood where students go to school. Youth in highly urbanized areas are more often confronted with multiple risk-increasing circumstances, such as poverty, broken families, crime, and drugs (Scientific Council for Government Policy 2008). Whereas our models estimate the unique contribution of each of those individual student characteristics to the explanation of variance in behavioral engagement, a combination of several risk factors may weigh more than the sum of its parts. An accumulation of risk factors among students in large cities may account for the negative effects of the three school boards in highly urbanized areas in our model. In addition, school populations in large cities comprise more at-risk students, which results in an accumulation of atrisk students within schools. Including measures of the composition of school populations in future research is useful to test whether the proportion of at-risk students in the student population can explain differences in the behavioral engagement between schools.

The importance of an interesting and activating academic program

Educational systems that place strong emphasis on vocational orientation and job-oriented training, like the Dutch system, have been suggested to promote school engagement (Symonds et al. 2011). The findings in this study confirm that a perceived fit with the academic program plays an important role in fostering students' behavioral engagement in SVE. If students experience that the academic program is interesting, and that the proportion of autonomous work that is required in the program is limited, they report higher levels of behavioral engagement. It is remarkable that a single measure of the perceived proportion of autonomous work in the program is more strongly related to behavioral engagement than any of the other school experience variables. Although adolescent students are assumed to develop a growing preference and ability to work autonomously (Eccles and Midgley 1989; Fredricks et al. 2004), the students in our study are more actively engaged if their program requires less autonomy. In public debates about recent educational reforms in the Netherlands, male adolescents have been said to experience particular difficulty with the increased autonomy in competency-based programs. Contrary to this view, we find that increased levels of autonomy are associated with lower behavioral engagement among female students only, and that male students are less engaged if there is little opportunity to work autonomously. Also, students in engineering programs, which 
predominantly attract male students, appear to prefer more autonomy in their programs. These findings raise several questions, for instance about the understanding of "autonomous work", which may differ substantially between programs and students. For instance, students in engineering programs may carry out clearly defined assignments individually in a workshop setting more often, whereas health and social care programs may include more open assignments and group collaboration. Moreover, student autonomy may result from deliberate pedagogical practices, with teachers carefully supporting their students to enact autonomy, but may also result from class management problems when teachers are not able to provide enough time and attention to individual students. Such potential differences have important consequences for the role and nature of autonomous work forms in school programs, and for students' experiences with autonomy in school. Moreover, even though more directive instruction and close supervision may increase participation in the classroom, schools might want to teach students to selfregulate their learning processes nevertheless, as part of the curriculum. All in all, our findings raise interesting questions about the best way to meet students' need for autonomy (Connell and Wellborn 1991) in the context of post-secondary vocational education, indicating that schools need to be careful not to push the level of autonomy in their programs too far.

\section{Divergent role of school experiences for at-risk and non-at-risk students}

The findings in this study confirm that school experiences play a key role in enhancing students' behavioral engagement in school (Fredricks et al. 2004). However, the relationship between school experiences and behavioral engagement differs according to students' background characteristics. What appears to stimulate active participation among one group of students may reduce the engagement of others. Education is not a matter of one-size-fits-all, and a diverse student body calls upon schools to tailor their programs and guidance towards the needs of individual students. One pattern of interaction effects warrants attention in particular. The behavioral engagement of certain groups of at-risk students seems to "benefit" less from positive school experiences. We found several indications of a weakened relationship between positive school experiences and behavioral engagement among at-risk students in our data. For instance, while positive perceptions of the support provided by school staff generally associate with higher levels of behavioral engagement, this relationship is significantly weaker for some at-risk students. We could interpret this result as an indication that support from school staff, or even a sense of relatedness in school, is less important for the school engagement of at-risk students than has been previously suggested (Furrer and Skinner 2003; Scientific Council for Government Policy 2008). An alternative interpretation is that, even if some at-risk students perceive that teachers and school staff are supportive, this support does not help them to become increasingly engaged in school to the same extent as other, non-at-risk, students. This could be due to a mismatch between the support provided by teachers and the particular needs of at-risk students, or to differences between at-risk and non-at-risk students with respect to the ability to strategically utilize the supportive resources available in the school environment. Such explanation suggests that teachers need to reach out more actively to at-risk students, to enable them to capitalize on the available resources and support in school, and that schools need to better tailor their support to the specific needs of those students. Another explanation for the weakened relationship could be the presence of disturbing circumstances in the personal lives of at-risk students. If students deal with substantial problems or responsibilities outside school, they are simply not able to devote enough time and attention to school, whether teachers are supportive or not. In such situations, cooperation between schools, social workers, and community organizations is needed, to help students solve these problems as much as possible, to enable them to focus on their school careers. 
Limitations and suggestions for future research

Research of the behavioral engagement of at-risk and non-at-risk students in Dutch SVE expands the current body of research on engagement and dropout processes that have been conducted primarily Anglo-Saxon school settings (Fredricks et al. 2004). In this study, we find that most indicators of an increased risk for dropout do not associate directly with patterns of behavioral disengagement in SVE. However, the findings indicate that an accumulation of risk factors within students and within schools, as well as a weakened relationship between positive school experiences and behavioral engagement among at-risk students, may explain why some students are more at risk of losing track in school. Future research that looks into these mechanisms, both in the context of SVE as well as in other educational settings and populations, could enhance our understanding of dropout processes worldwide. Furthermore, the important role of perceived autonomy on students' behavioral engagement, and the differences found between males and females and vocational sectors with respect to this role, calls for further research. The single-item variable that was used to measure perceived autonomy in this study cannot capture the many interpretations and forms that autonomy can take in the wide range of existing educational and group settings in vocational education. More in-depth research of autonomy support and self-regulation processes in vocational education could provide better insights into the needs and preferences regarding autonomous work forms across student groups and vocational settings.

In addition, this study has some general methodological limitations that need to be considered when considering the implications of its results. First, as all measures are based on students' self-report, we need to be aware of common method bias, which refers to respondents' tendency to report consistent attitudes throughout all sections of the questionnaire (Podsakoff et al. 2003). Second, given the cross-sectional nature of our data, no causal inferences can be made. It is likely that most relationships between school experiences and behavioral engagement are reciprocal. Future research can benefit from the continuation of our longitudinal project on student persistence in SVE, which will yield data that not only allow for assessment of relationships between school experiences and engagement over a longer period of time but also for the examination of relationships between school engagement and dropout in SVE. If we understand which aspects of the school experience particularly help or hinder students' engagement and persistence in school, we can assist all students, both at-risk and non-at-risk, better to stay on track in school.

Open Access This article is distributed under the terms of the Creative Commons Attribution License which permits any use, distribution, and reproduction in any medium, provided the original author(s) and the source are credited.

\section{References}

Alexander, K. L., Entwisle, D. R., \& Bedinger, S. D. (1994). When expectations work: race and socioeconomic differences in school performance. Social Psychology Quarterly, 57(4), 283-299.

Alexander, K. L., Entwisle, D. R., \& Kabbani, N. S. (2001). The dropout process in life course perspective: early risk factors at home and school. Teachers College Record, 103(5), 760-822.

Appleton, J. J., Christenson, S. L., Kim, D., \& Reschly, A. L. (2006). Measuring cognitive and psychological engagement: validation of the student engagement instrument. Journal of School Psychology, 44, 427-445. 
Astone, N. M., \& McLanahan, S. S. (1991). Family structure, parental practices and high school completion. American Sociological Review, 56(3), 309-320.

Audas, R., \& Willms, J. D. (2001). Engagement and dropping out of school: a life-course perspective. Quebec: HRDC Publications Centre.

Barrington, B. L., \& Hendricks, B. (1989). Differentiating characteristics of high school graduates, dropouts, and nongraduates. The Journal of Educational Research, 82(6), 309-319.

Battin-Pearson, S., Newcomb, M. D., Abbott, R. D., Hill, K. G., Catalano, R. F., \& Hawkins, J. D. (2000). Predictors of early high school dropout: a test of five theories. Journal of Educational Psychology, 92(3), 568-582.

Baumeister, R. F., \& Leary, M. R. (1995). The need to belong: desire for interpersonal attachments as a fundamental human motivation. Psychological Bulletin, 117(3), 497-529.

Beekhoven, S. (2002). A fair chance of succeeding-study careers in Dutch higher education. Amsterdam: $\mathrm{SCO}-$ Kohnstamm Instituut.

Bridgeland, J. M., DiIuliou, J. J., \& Morison, K. B. (2006). The silent epidemic. Perspectives of high school dropouts. Washington: Civic Enterprises.

Connell, J. P., \& Wellborn, J. G. (1991). Competence, autonomy and relatedness: a motivational analysis of self-system processes. In M. R. Gunnar \& L. A. Stroufe (Eds.), Self-processes and development: the Minnesota symposia on child psychology (Vol. 23). Hillsdale: Erlbaum.

Connell, J. P., Spencer, M. B., \& Aber, J. L. (1994). Educational risk and resilience in African-American youth: context, self, action, and outcomes in school. Child Development, 65(2), 493-506.

Crumpton, H. E., \& Gregory, A. (2011). "I'm not learning": the role of academic relevancy for low-achieving students. The Journal of Educational Research, 104(1), 42-53.

Dijsselbloem, C. (2008). Tijd voor onderwijs [Time for education]. The Hague: SDU.

Dutch Ministry of Education Culture and Science. (2009). VSV Atlas [Dropout atlas]. The Hague: Ministerie van OCW.

Dutch Ministry of Education Culture and Science. (2011a). Bijlage VSV-brief 2011 [Appendix dropout circular 2011]. The Hague: OCW.

Dutch Ministry of Education Culture and Science. (2011b). Kerncijfers 2006-2010 [Primary Statistics 20062010]. The Hague: OCW.

Dutch Ministry of Health Welfare and Sport. (2010). Nationaal kompas volksgezondheid—bevolkingscholing en opleiding [National compass public health-population-education]. Retrieved 11/11/10, from www.nationaalkompas.nl/bevolking/scholing-en-opleiding

Eccles, J. (1983). Expectancies, values, and academic behaviors. In J. T. Spence (Ed.), Achievement and achievement motives. Psychological and sociological approaches. San Francisco: Freeman.

Eccles, J., \& Midgley, C. (1989). Stage-environment fit: developmentally appropriate classrooms for young adolescents. In C. Ames \& R. Ames (Eds.), Research on motivation in education. Volume 3: goals and cognitions. San Diego: Academic.

Ekstrom, R. B., Goertz, M. E., Pollack, J. M., \& Rock, D. A. (1986). Who drops out of high school and why? Findings from a national study. Teachers College Record, 87(3).

Finn, J. D. (1989). Withdrawing from school. Review of Educational Research, 59(2), 117-142.

Finn, J. D. (1993). School engagement and students at risk. Washington: National Center for Educational Statistics.

Finn, J. D., \& Rock, D. A. (1997). Academic success among students at risk for school failure. Journal of Applied Psychology, 82(2), 221-234.

Finn, J. D., \& Voelkl, K. E. (1993). School characteristics related to student engagement. The Journal of Negro Education, 62(3), 249-268.

Fredricks, J. A., Blumenfeld, P. C., \& Paris, A. H. (2004). School engagement: potential of the concept, state of the evidence. Review of Educational Research, 74(1), 59-109.

Freeman, T. M., Anderman, L. H., \& Jensen, J. M. (2007). Sense of belonging in college freshmen at the classroom and campus levels. The Journal of Experimental Education, 75(3), 203-220.

Furrer, C., \& Skinner, E. (2003). Sense of relatedness as a factor in children's academic engagement and performance. Journal of Educational Psychology, 95(1), 148-162.

Goodenow, C., \& Grady, K. E. (1993). The relationship of school belonging and friends' values to academic motivation among urban adolescent students. The Journal of Experimental Education, 62(1), 60-71.

Jang, H., Reeve, J., \& Deci, E. L. (2010). Engaging students in learning activities: it is not autonomy support or structure but autonomy support and structure. Journal of Educational Psychology, 102(3), 588-600.

Janosz, M., Le Blanc, M., Boulerice, B., \& Tremblay, R. E. (2000). Predicting different types of school dropouts: a typological approach with two longitudinal samples. Journal of Educational Psychology, 92 (1), 171-190.

Jimerson, S. R., Anderson, G. E., \& Whipple, A. D. (2002). Winning the battle and losing the war: examining the relation between grade retention and dropping out of high school. Psychology in the Schools, 39(4), $441-457$. 
Kao, G., \& Tienda, M. (1998). Educational aspirations of minority youth. American Journal of Education, $106(3), 349-384$.

Knowledge Centre for Vocational Training and Labour Market. (2010). 4e Benchmark middelbaar beroepsonderwijs-bouwsteen studiesucces [4th benchmark senior vocational education-student success]. Nijmegen: KBA.

Kuhry, B. (1998). Trends in onderwijsdeelname [Trends in educational participation] (Vol. Sociale en culturele studies-25). Rijswijk: SCP.

Lee, J. C., \& Staff, J. (2007). When work matters: the varying impact of work intensity on high school dropout. Sociology of Education, 80(April), 158-178.

Marks, H. M. (2000). Student engagement in instructional activity: patterns in elementary, middle, and high school years. American Educational Research Journal, 37(1), 153-184.

Miller, S. E., Leinhardt, G., \& Zigmond, N. (1988). Influencing engagement through accommodation: an ethnographic study of at-risk students. American Educational Research Journal, 25(4), 465-487.

National Research Council, \& Institute of Medicine. (2004). Engaging schools: fostering high school students' motivation to learn. Washington: The National Academies Press.

Newmann, F. M. (1992). The significance and sources of student engagement. In F. M. Newmann (Ed.), Student engagement and achievement in American secondary schools. New York: Teachers College Press.

Pascarella, E. T., \& Chapman, D. W. (1983). A multi-institutional, path analytic validation of Tinto's model of college withdrawal. American Educational Research Journal, 20(1), 87-102.

Pascarella, E. T., \& Terenzini, P. T. (2005). How college affects students: a third decade of research. San Francisco: Jossey-Bass.

Podsakoff, P. M., MacKenzie, S. B., Lee, J.-Y., \& Podsakoff, M. P. (2003). Common method biases in behavioral research: a critical review of the literature and recommended remedies. Journal of Applied Psychology, 88(5), 879-903.

Reeve, J., Deci, E. L., \& Ryan, R. M. (2004). Self-determination theory: a dialectical framework for understanding sociocultural influences on student motivation. In D. M. McInerney \& S. Van Etten (Eds.), Big theories revisited. Greenwich: Information Age.

Research Centre for Education and the Labour Market. (2009). Zonder diploma. Aanleiding, kansen en toekomstintenties [Without a diploma. Causes, chances, and future intentions]. Maastricht: ROA.

Roderick, M. (1993). The path to dropping out. Evidence for intervention. Westport: Auburn House.

Roderick, M., \& Camburn, E. (1999). Risk and recovery from course failure in the early years of high school. American Educational Research Journal, 36(2), 303-343.

Roebuck, M. C., French, M. T., \& Dennis, M. L. (2004). Adolescent marijuana use and school attendance. Economics of Education Review, 23(2004), 133-141.

Roeser, R. W., Urdan, T. C., \& Stephens, J. M. (2009). Schools as a context of student motivation and achievement. In K. R. Wentzel \& A. Wigfield (Eds.), Handbook of motivation at school. New York: Routledge.

Rumberger, R. W. (1987). High school dropouts: a review of issues and evidence. Review of Educational Research, 57(2), 101-121.

Rumberger, R. W., \& Lim, S. A. (2008). Why students drop out of school: a review of 25 years of research: California Dropout Research Project (C. D. R. Project o. Document Number)

Scientific Council for Government Policy. (2008). Vertrouwen in de school [Trust in the school]. Amsterdam: Amsterdam University Press.

Snijders, T. A. B., \& Bosker, R. J. (1999). Multilevel analysis: an introduction to basic and advanced multilevel modeling. London: Sage.

SPSS Inc. (2010). PASW statistics 17.0 command syntax reference. Chicago: SPSS.

Steinberg, L., Dornbusch, S. M., \& Brown, B. B. (1992). Ethnic differences in adolescent achievement: an ecological perspective. American Psychologist, 47(6), 723-729.

Symonds, W. C., Schwartz, R. B., \& Ferguson, R. (2011). Pathways to prosperity: meeting the challenge of preparing young Americans for the 21st century. Cambridge: Harvard Graduate School of Education.

ter Bogt, T., van Lieshout, M., Doornwaard, S., \& Eijkemans, Y. (2009). Middelengebruik en voortijdig schoolverlaten [Substance abuse and early school leaving]. Utrecht: Trimbos Instituut.

Tinto, V. (1993). Leaving college. Rethinking the causes and cures of student attrition. Chicago: University of Chicago Press.

Verhagen, S., van Heijst, P., Jurrius, K., Calkoen, P., \& Koot, E. (2010). Rood staan is geen schuld [Being in the red is no debt]. Tijdschrift voor sociale vraagstukken, 2010(7-8), 8-11.

Voelk1, K. E. (1995). School warmth, student participation, and achievement. The Journal of Experimental Education, 63(20), 127-138.

Wang, M.-T., Selman, R. L., Dishion, T. J., \& Stormshak, E. A. (2010). A tobit regression analysis of the covariation between middle school students' perceived school climate and behavioral problems. Journal of Research on Adolescence, 20(2), 274-286. 
Wehlage, G. G., Rutter, R. A., Smith, G. A., Lesko, N., \& Fernandez, R. R. (1989). Reducing the risk. Schools as communities of support. Philadelphia: Falmer.

Wessel, J. L., Ryan, A. M., \& Oswald, F. L. (2008). The relationship between objective and perceived fit with academic major, adaptability, and major-related outcomes. Journal of Vocational Behavior, 72(3), 363376.

Willms, J. D. (2003). Student engagement at school. A sense of belonging and participation. Results from PISA 2000. OECD.

Zimmer-Gembeck, M. J., Chipuer, H. M., Hanisch, M., Creed, P. A., \& McGregor, L. (2006). Relationships at school and stage-environment fit as resources for adolescent engagement and achievement. Journal of Adolescence, 29(6), 911-933.

Louise Elffers. Research Institute Child Development and Education, University of Amsterdam, P.O. Box 94208, 1090 GE Amsterdam, The Netherlands. E-mail: 1.elffers@uva.nl; URL: www.uva.nl

Current themes of research:

Interests concern social and academic determinants of educational attainment. (in)equality in educational opportunities. Educational organization and policy, with a specific interest in vocational education.

Most relevant publications in the field of Psychology of Education:

Elffers, L. (2012). Staying on track: behavioral engagement of at-risk and non-at-risk students in postsecondary vocational education. European Journal of Psychology of Education. doi: 10.1007/s10212-012-0128-3.

Elffers, L., Oort, F. J., \& Karsten, S. (2012). Making the connection: The role of social and academic school experiences in students' emotional engagement with school in post-secondary vocational education. Learning and Individual Differences, 22(2), 242-250. 